\title{
Frontal Sinus Pattern and Evaluation of Right and Left Frontal Sinus Volume According to Gender, Using Multi Detector CT Scan
}

\author{
Nateghian $\mathrm{Z}^{* 1}$, Abedi $\mathrm{I}^{2}$, Dashti $\mathrm{GH}^{3}$ and Faraji $\mathrm{B}^{4}$ \\ ${ }^{1}$ MS Student of Anatomy Sciences, Isfahan University of Medical Sciences, Isfahan, Iran \\ ${ }^{2}$ Ph.D. Student of Medical Physics, Isfahan University of Medical Sciences, Isfahan, Iran \\ ${ }^{3}$ Associate Professor of Anatomy Faculty, Isfahan University of Medical Sciences, Isfahan, Iran \\ ${ }^{4}$ MS Student of Medical Physics, Isfahan University of Medical Sciences, Isfahan, Iran
}

${ }^{*}$ Corresponding author: Nateghian Z, MS Student of Anatomy Sciences, Isfahan University of Medical Sciences, Isfahan, Iran, E-mail: nateghianzohreh@gmail.com

Citation: Nateghian Z, Abedi I, Dashti GH, Faraji B (2016) Frontal Sinus Pattern and Evaluation of Right and Left Frontal Sinus Volume According to Gender, Using Multi Detector CT Scan. J Forensic Sci Criminol 4(4): 402. doi: $10.15744 / 2348-9804.4 .402$

Received Date: February 27, 2016 Accepted Date: August 29, 2016 Published Date: August 30, 2016

\begin{abstract}
Background: Frontal sinuses are pneumatic cavities that radiologically revealed in 5 or 6 years old and completed in 20 years old. Comparison of the frontal sinus has significant value to establish identification. The purpose of this study was to comparison of frontal sinus and assessment of right and left frontal sinus volume according to gender by using Multi Detector CT scan (MDCT).

Materials and Methods: Sixty five consecutive men's and women's patients who underwent paranasal CT scans from September 2014 to April 2016 were identified from our institutional imaging database. Height, depth, and width of frontal sinuses were measured and a cubical approximation of volume determined by using Digimizer Image Analyzer.

Result: Right and left frontal sinus were observed in 44 individuals (67.8\%). Right frontal sinus was absent in 6 individuals (9.2\%) and left frontal sinus was absent in 3 individuals (4.6\%). Both of frontal sinus were absent in 9 individuals (13.8\%). Right and left frontal sinus were not separate (integration) in 3 individuals (4.6\%). Lack of frontal sinus frequency was higher in men and sinus integration was seen only in women.The average volume in left sinus was significantly higher than the right $(\mathrm{P}=0.02)$. Average volume of both the right $(\mathrm{P}=0.04)$ and the left $(\mathrm{P}=0.02)$ frontal sinus in males were significantly more than females.

Conclusion: We found that the frontal sinus patterns had considerable individual variation. Right and left frontal sinus volumes were variable according to gender by using CT scan.
\end{abstract}

Keywords: Frontal Sinus Pattern; Gender; Multi Detector CT Scan

\section{Introduction}

The paranasal sinuses begin development early in fetal life. The functions of these sinuses are not fully understood, but most anatomical literature suggests that they lighten the skull and add resonance to the voice [1-5]. Among the four major sinuses present in the human skull, namely, the maxillary, frontal, sphenoidal, and ethmoidal. Considerable forensic interest in identification has been shown in the frontal sinus [6-9]. Comparison of the frontal sinus has significant value to establish identification. Frontal sinuses are pneumatic cavities that become radiologically evident at the age of five or six years and develop fully by the age of 20 years [10]. The definitive frontal sinuses are paired, irregular shaped, air-containing chambers, lined by mucoperiosteum and are located between the outer and inner tables of the frontal bone, posterior to the super ciliary arches and at the root of the nose [1-3].

Studies have suggested that the frontal sinuses are slightly bigger in males than in females, and the presence of a metopic suture is associated with the absence of the frontal sinuses [11,12].

It has been suggested that frontal sinus patterns have a potential to be used as aids for personal identification, age estimation, and sexual dimorphism [10,13-17].

With this background, this study was undertaken to examine and classify variations in frontal sinus and assessment of right and left frontal sinus volume according to sex by using CT scan. 


\section{Patients and Methods}

\section{Study design}

This prospective study was institutional review board approved and informed consent was obtained from all patients. Sixty six consecutive men's and women's patients (average age, 45 years; age range, 35-55 years) who underwent paranasal CT scans from September 2014 to April 2016 were identified from our institutional imaging database.

Inclusion criteria were patients with axial paranasal or facial CT scans. Exclusion criteria included patients with incomplete imaging, previous cranial injury or surgery, and penetrating trauma.

\section{Imaging Parameters}

All initial CT scans were performed on a 64-detector scanner (Siemens, model; sensation). Imaging of the paranasal CT was performed with helical axial reconstructions $(140 \mathrm{kVp}, 50 \mathrm{mAs}): 1 \mathrm{~mm}$ reconstructed slice thickness; $0.5 \mathrm{~mm}$ increment (WW 3000, WL600) [18].

\section{Measurement of Frontal Sinus Volume}

Paranasal CT scans were used to measure the dimensions of the frontal sinus. At first, the patient's upper extremities were kept adjacent to the body, Orbito Meatal Base Line (OMBL) was perpendicular to the bed. Area was measured in the axial plane. A cubical approximation of volume was determined for each frontal sinus in both gender by plus measurements of area in axial planes then plus thickness and increment for each plan then multiplying both sum. Right and left sinuses of each patient were compared, too.

\section{Results}

Sixty six consecutive men's (41 individuals, (63.1\%)) and women's (24 individuals were females (36.9\%)) patients who underwent paranasal CT scans from September 2014 to April 2016 were identified from our institutional imaging database. Height, depth, and width of frontal sinuses were measured and a cubical approximation of volume was determined by using Digimizer Image Analyzer (MedCalc Software). At first, unit of measurement was defined then perimeters and areas were measured. We classified variations in frontal sinus according to gender by using CT scan:

Right and left frontal sinus was observed in 44 individuals (67.8\%) (73.2\% of males and 58.3\% of females).

Left frontal sinus was absent in 3 individuals (4.6\%) (4.9\% of males and 4.2\% of females) and right frontal sinus was absent in 6 individuals $(9.2 \%)$ (4.9\% of males and $16.7 \%$ of females).

Both of frontal sinus were absent (bilateral aplasia) in 9 individuals (13.8\%) (17.1\% of male and $8.3 \%$ of female). Right and left frontal sinus were not separate (integration) in 3 individuals (4.6\%) (12.5\% of female)

Likelihood Ratio Chi-Square test Showed that the frequency of the frontal sinus pattern was significantly different between women and men $(\mathrm{P}=0.04)$.

As the Table 1 shows a lack of frontal sinus frequency is higher in men and sinus integration was seen only in women (Table 2 and $3)$.

\begin{tabular}{|c|c|c|c|}
\hline Frontal sinus patterns & Males n (\%) & Females n (\%) & Total n (\%) \\
\hline Right and left Frontal sinus & $(73.2 \%)$ & $(58.3 \%)$ & 44 individuals (67.8\%) \\
\hline Absence left Frontal sinus & $(4.9 \%)$ & $(4.2 \%)$ & 3 individuals (4.6\%) \\
\hline Absence right Frontal sinus & $(4.9 \%)$ & $(16.7 \%)$ & 6 individuals (9.2\%) \\
\hline bilateral aplasia & $(17.1 \%)$ & $(8.3 \%)$ & 9 individuals (13.8\%) \\
\hline integration & 0 & $(12.5 \%)$ & 3 individuals (4.6\%) \\
\hline
\end{tabular}

Table 1: Descriptive analysis of frontal sinus patterns

\begin{tabular}{|c|c|c|c|}
\hline Side & Mean \pm SE & Min & Max \\
\hline Right sinus & $1.807 \pm 0.196$ & 0.236 & 7.720 \\
\hline Left sinus & $2.088 \pm 0.248$ & 0.273 & 9.476 \\
\hline
\end{tabular}

Table 2: Average volume of the left and right frontal sinus

Paired $t$-test showed that the average volume in the left sinus was significantly higher than the right $(\mathrm{P}=0.02)$. Pearson correlation coefficients showed that there was a direct relationship between the right and left sinus $(\mathrm{P}<0.001, \mathrm{r}=0.813)$ 


\begin{tabular}{|c|c|c|c|}
\hline Side & $\begin{array}{c}\text { Males } \\
\text { Mean } \pm \text { SE }\end{array}$ & $\begin{array}{c}\text { Females } \\
\text { Mean } \pm \text { SE }\end{array}$ & P-value \\
\hline Right sinus & $1.884 \pm 0.197$ & $1.642 \pm 0.458$ & 0.04 \\
\hline Left sinus & $2.284 \pm 0.281$ & $1.738 \pm 0.476$ & 0.02 \\
\hline
\end{tabular}

Table 3: Shows Average volume of the left and right frontal sinus according to gender

Independent $t$ - test showed that average volume of both the right $(\mathrm{P}=0.04)$ and the left $(\mathrm{P}=0.02)$ frontal sinus in males significantly more than females

\section{Discussion}

Like fingerprints, sinus patterns are unique for a person. Identification by comparing the frontal sinus radiographs dramatically valid because no two people are the same frontal sinus configuration. Apart from radiographs from normal traditional projection methods, CT scans of frontal sinus have also been used for identification [9]. However, there are possibilities that the frontal sinus being absent altogether. Furthermore, unlike fingerprints, frontal sinuses are affected by pathology such as acute or chronic inflammations, some endocrine dysplasia, osteitis, and trauma $[6,19]$.

Individuals were selected randomly between the ages 25 and 50 years, due to the fact that the development of the frontal sinus goes up to 20 years and comparison for identification must be restricted to persons over the age of 20 years when definite morphology is established after a rapid development during puberty $[6,20]$. In our study, right and left frontal sinus was found in $67.7 \%$ of the individuals. Only right frontal sinus was observed in $4.6 \%$ and only left Frontal sinus was seen in $9.2 \%$ of the individuals. Bilateral aplasia was found in $13.8 \%$. The results were consistent with those of Krogman, who observed frontal sinus absence in $5 \%$ of the adults, while Gulisano, et al. observed its absence in $4.8 \%$ of the cases $[19,21,22]$. Frontal sinus was not separate (integration) in $4.6 \%$ of the individuals in our sample. The frequency of the frontal sinus pattern was significantly different between women and men $(\mathrm{P}=0.04)$.

Lack of frontal sinus frequency was higher in men and Sinus integration was seen only in women.

The average volume in the left sinus was significantly higher than the right $(\mathrm{P}=0.02)$. There was a direct relationship between the right and left sinus $(\mathrm{P}<0.001, \mathrm{r}=0.813)$.Average volume of both the right $(\mathrm{P}=0.04)$ and the left $(\mathrm{P}=0.02)$ frontal sinus in males were significantly more than females.

\section{References}

1. Hollinshead WH (1954) Anatomy for surgeons Vol 1: The head and neck. Postgrad Med J.

2. Williams PL (1989) Gray's anatomy: Churchill livingstone Edinburgh.

3. Sperber GH (2006) Clinically Oriented Anatomy. J Anat 208: 393.

4. Sinnatamby CS (2011) Last's anatomy: regional and applied. Elsevier Health Sciences.

5. Snell RS, Travill, Anthony AMB (1979) Clinical Anatomy for Medical Students. Annals of Plastic Surgery 2: 542.

6. Harris AM, Wood RE, Nortjé CJ, Thomas CJ (1987) The frontal sinus: forensic fingerprint? A pilot study. J Forensic Odontostomatol 5: 9-15.

7. Harris AM, Wood RE, Nortje CJ, Thomas CJ (1987) Gender and ethnic differences of the radiographic image of the frontal region. J Forensic Odontostomatol 5: $51-7$.

8. Kullman L, Eklund B, Grundin R (1990) Value of the frontal sinus in identification of unknown persons. J Forensic Odontostomatol 8: 3-10.

9. Reichs KJ (1993) Quantified comparison of frontal sinus patterns by means of computed tomography. Forensic Sci Int 61: 141-68.

10. Silva RF, Pinto RN, Ferreira GM, Daruge Júnior E (2008) Importance of frontal sinus radiographs for human identification. Braz J Otorhinolaryngol 74: 798.

11. Schuller A (1943) A note on the identification of skulls by x-ray pictures of the frontal sinuses. Med J Aust 1: 554-6.

12. Brown WA, Molleson TI, Chinn S (1984) Enlargement of the frontal sinus. Annals of human biology 11: 221-6.

13. Tang JP, Hu DY, Jiang FH, Yu XJ (2009) Assessing forensic applications of the frontal sinus in a Chinese Han population. Forensic Sci Int 183: 104.

14. Quatrehomme G, Fronty P, Sapanet M, Grévin G, Bailet P, et al. (1996) Identification by frontal sinus pattern in forensic anthropology. Forensic Sci Int 83: 147-53.

15. Prossinger H (2001) Sexually dimorphic ontogenetic trajectories of frontal sinus cross sections. Coll Antropol 25: 1-11.

16. Taniguchi M, Sakoda S, Kano T, Zhu BL, Kamikodai Y, et al. (2003) Possible Use of Nasal Septum and Frontal Sinus Patterns to Radiographic Identification of Unknown Human Remains. Osaka City Med J 49: 31-8.

17. Ruf S, Pancherz H (1996) Can frontal sinus development be used for the prediction of skeletal maturity at puberty? Acta Odontol Scand 54: 229-34.

18. Nemec SF, Peloschek P, Koelblinger C, Mehrain S, Krestan CR, et al. (2009) Sinonasal imaging after Caldwell-Luc surgery: MDCT findings of an abandoned procedure in times of functional endoscopic sinus surgery. Eur J Radiol 70: 31-4.

19. Iscan MY, Steyn M (2013) The human skeleton in forensic medicine: Charles C Thomas Publisher.

20. Yoshino M, Miyasaka S, Sato H, Seta S (1987) Classification system of frontal sinus patterns by radiography. Its application to identification of unknown skeletal remains. Forensic Sci Int 34: 289-99.

21. Gulisano M, Pacini P, Orlandini GE (1978) Frontal sinus dimensions in relation to the cranial index: anatomo-radiologic findings. Boll Soc Ital Biol Sper 54: 66-9. 
22. Stewart T, Krogman WM (1962) The Human Skeleton in Forensic Medicine. JSTOR.

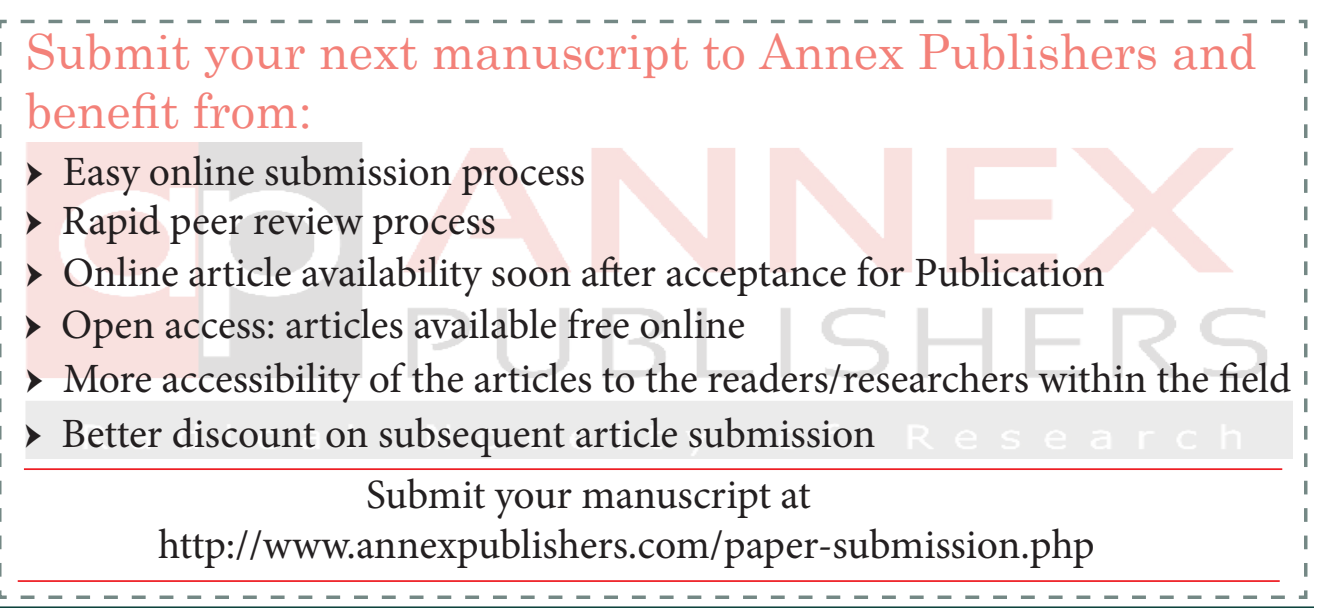

